\title{
Reação de subamostras de feijão-fava à antracnose
}

\author{
Gerusa Rodrigues dos Santos Cavalcante, Eulália Maria Sousa Carvalho, Regina Lucia Ferreira Gomes, Ananda \\ Rosa Beserra Santos, Cleidiane Maria Pereira Marques Santos
}

Universidade Federal do Piauí (UFPI), Centro de Ciências Agrárias, Departamento de Fitotecnia - Campus da Socopo S/N, 64.049-550, Teresina, PI. Parte da dissertação da primeira autora. Bolsista FAPEPI.

Autor para correspondência: Eulália Maria S. Carvalho (eulaliamsc@yahoo.com.br)

Data de chegada: 25/05/2012. Aceito para publicação em: 13/09/2012.

\section{RESUMO}

Cavalcante, G.R.S.; Carvalho, E.M.S.; Gomes, R.L.F.; Santos, A.R.B.; Santos, C.M.P.M. Reação de subamostras de feijão-fava à antracnose Summa Phytopathologica, v.38, n.4, p.329-333, 2012.

O feijão-fava, segunda espécie mais cultivada do gênero Phaseolus, apesar de demonstrar grande adaptação às condições edafoclimáticas na região Nordeste do Brasil, apresenta baixo rendimento devido, entre outros fatores, à ocorrência de doenças como a antracnose, causada pelo fungo Colletotrichum truncatum. Nesse sentido, objetivou-se avaliar a reação de 30 subamostras de feijão-fava à antracnose. Para tanto, foram utilizadas folhas destacadas inoculadas com C. truncatum. A severidade da doença foi estimada por meio de escala de notas e as subamostras agrupadas em cinco classes de acordo com a resistência. O delineamento utilizado foi o inteiramente casualizado com quatro repetições. Em folhas destacadas, a maioria das subamostras de feijão-fava apresentou baixo nível de resistência à antracnose. As subamostras UFPI 251 e UFPI 673 comportaram-se como altamente resistentes aos cinco e sete dias após a inoculação sendo, portanto, promissoras para utilização em programas de melhoramento da cultura.

Palavras-chave adicionais: Phaseolus lunatus, Colletotrichum, fitopatógeno, resistência genética.

\section{ABSTRACT}

Cavalcante, G.R.S.; Carvalho, E.M.S.; Gomes, R.L.F.; Santos, A.R.B.; Santos, C.M.P.M. Lima Bean subsample reaction to anthracnose. Summa Phytopathologica, v.38, n.4, p.329-333, 2012.

Lima bean, the second most cultivated species of the genus Phaseolus, in spite of demonstrating great adaptation to the edaphoclimatic conditions in the northeast region of Brazil, shows low yield due to the occurrence of diseases such as anthracnose, which is caused by the fungus Colletotrichum truncatum. Thus, this study aimed to evaluate the reaction of 30 Lima bean subsamples to anthracnose. Detached leaves inoculated in C. truncatum were used. The disease severity was estimated based on a grade scale and the subsamples were grouped into five classes according to resistance. Experimental design was completely randomized (CRD) with four replicates. The detached leaves from Lima bean subsamples showed a low resistance level to anthracnose. The subsamples UFPI 251 and UFPI 673 behaved as highly resistant at five and seven days after inoculation, showing thus promising to be used in breeding programs for this crop.

Additional keywords: Phaseolus lunatus, Colletotrichum, phytopathogen, genetic resistance.

A fava (Phaseolus lunatus L.), também conhecida como feijãolima ou feijão-fava, é uma planta anual da família das leguminosas, trepadeira e cultivada por apresentar grãos comestíveis (1). A espécie foi domesticada na América do Sul e Central, e é considerada subtropical $(22,23)$.

O feijão-fava tem relativa importância econômica e social por causa da sua rusticidade, com colheita prolongada e realizada no período seco (1). Apresenta maior adaptabilidade que o feijão-comum (Phaseolus vulgais L.) (11). É a segunda leguminosa de maior importância do gênero Phaseolus e, devido ao conteúdo protéico, é usada como fonte alternativa de alimento na forma de grãos maduros ou verdes ou como opção de renda, principalmente por pequenos produtores (21).

Segundo Santos et al. (20), a cultura do feijão-fava apresenta baixa produtividade, que pode ser atribuída ao fato de parte da produção ser oriunda de pequenos produtores que o plantam em consórcios com outras culturas, sem a adoção de tecnologia que vise o aumento da produtividade. A ocorrência de doenças também tem sido apontada como um dos fatores de redução da produtividade e da qualidade da fava produzida. Entre essas doenças, a antracnose, causada pelo fungo Colletotrichum truncatum (Schw.) Andrus \& Moore, tem se destacado entre as doenças fúngicas frequentemente encontradas em plantios de feijão-fava no Brasil, especialmente na região Nordeste (17).

O uso de cultivares resistentes tem sido um dos métodos de controle mais eficientes, pois além de diminuir o custo de produção reduz os impactos negativos ao ambiente pela aplicação de agrotóxicos. Segundo Camargo \& Bergamin Filho (4), a primeira etapa básica em qualquer programa de obtenção e utilização de cultivares resistentes é identificar fontes de resistência, ou seja, identificar germoplasma que possua os genes de resistência de interesse. Desta forma, avaliar a reação do germoplasma de feijão-fava à antracnose é importante para auxiliar no desenvolvimento de cultivares com maior resistência ou tolerância a essa doença.

A técnica da folha destacada tem sido usada para avaliar resistência 
a doenças de várias culturas destacando-se o feijão (19), a soja (10) e o próprio feijão-fava (6). O seu emprego, segundo Medeiros (12), apresenta como vantagens a economia de espaço, de material do hospedeiro, de inóculo dos patógenos e facilidade de obtenção e exatidão das observações, menor risco de contaminações, uniformidade da unidade experimental, facilidade de controle e manipulação dos ambientes experimentais. Em feijão-fava, Carvalho (6) constatou correlação positiva e significativa na reação de genótipos a $C$. truncatum quando avaliados em planta e folhas destacadas, comprovando a viabilidade do emprego dessa técnica em estudos relacionados a esta doença. Nesse sentido, objetivou-se avaliar a resistência de subamostras de feijão-fava a C. truncatum por meio da técnica da folha destacada.

\section{MATERIAL E MÉTODOS}

O experimento foi realizado no período de janeiro a abril de 2010, no Centro de Ciências Agrárias (CCA) da Universidade Federal do Piauí (UFPI), em Teresina - Piaú, localizada a $05^{\circ} 02^{\prime} 45^{\prime \prime S}$ e $42^{\circ} 46^{\prime} 57^{\prime \prime W}$.

\section{Origem do isolado de $C$. truncatum}

$\mathrm{O}$ isolado de $C$. truncatum foi obtido de folhas de feijão-fava com sintomas característicos de antracnose, coletadas no campo experimental do CCA.

As culturas puras foram obtidas empregando-se o método indireto, no qual fragmentos do tecido foliar doente, após desinfestação superficial em álcool $70 \%$ durante um minuto e hipoclorito de sódio a $2 \%$ por dois minutos, foram transferidos para placas de Petri contendo meio ágar-água a $2 \%$ e mantidas a $28 \pm 1^{\circ} \mathrm{C}$ e fotoperíodo de 12 horas. À medida que o micélio tornou-se perceptível efetuou-se a transferência para o meio feijão-dextrose-ágar (FDA), constituído de $200 \mathrm{~g}$ de feijãocomum, grão tipo carioca, cozido em forno micro-ondas por 20 minutos, em potência máxima, acrescido de $20 \mathrm{~g}$ de dextrose e $16 \mathrm{~g}$ de ágar, para posterior caracterização sendo denominado isolado CT4.

\section{Avaliação da resistência de subamostras de feijão-fava à antracnose}

Foram empregadas folhas destacadas de 30 subamostras de feijãofava oriundas do Banco Ativo de Germoplasma (BAG de Feijão-fava) da UFPI e selecionadas por serem raças locais e/ou utilizadas por

Tabela 1. Relação das subamostras de feijão-fava avaliadas em Teresina-PI, 2010.

\begin{tabular}{|c|c|c|c|c|}
\hline Subamostra & Nome popular & Local de coleta & Hábito de crescimento & Cor da semente \\
\hline Progênie $1^{*}$ & NI & $\mathrm{NI}$ & Indeterminado & Branca com hilo rajado \\
\hline Progênie $2 *$ & $\mathrm{NI}$ & NI & Indeterminado & Branca com hilo rajado \\
\hline UFPI 655 & Boca de moça & Olho d’água/PI & Indeterminado & Branca com hilo rajado \\
\hline UFPI 220 & BGH883/92 & Ipameri/GO & Indeterminado & Marrom \\
\hline UFPI 121 & NI & Bom Jesus/PI & Indeterminado & Amarela \\
\hline UFPI 251 & BGH-780/92 & Cáceres/MG & Indeterminado & Cinza claro \\
\hline UFPI 656 & Boca de moça & Barro Duro/PI & Indeterminado & Branca com hilo rajado \\
\hline UFPI 667 & Boca de moça & Palmeirais/PI & Indeterminado & Branca com hilo rajado \\
\hline UFPI 664 & Boca de moça & Riachinho/PI & Indeterminado & Branca com hilo rajado \\
\hline UFPI 276 & Pintada roxa & Cajazeiras/PB & Indeterminado & Roxa pintada \\
\hline UFPI 222 & BGH $882 / 92$ & Ipameri/GO & Indeterminado & Marrom \\
\hline UFPI 465 & $\mathrm{NI}$ & Mirador/MA & Indeterminado & Creme \\
\hline UFPI 679 & Boca de moça & $\mathrm{Picos} / \mathrm{PI}$ & Indeterminado & Branca com hilo rajado \\
\hline UFPI 658 & Boca de moça & Palmeirais/PI & Indeterminado & Branca com hilo rajado \\
\hline UFPI 659 & Boca de moça & Barro Duro/PI & Indeterminado & Branca com hilo rajado \\
\hline UFPI 032 & NI & Várzea Grande/PI & Indeterminado & Marrom \\
\hline UFPI 494 & Fígado de galinha & Açailândia/MA & Indeterminado & Marrom claro \\
\hline UFPI 470 & NI & Teresina/PI & Indeterminado & Creme \\
\hline UFPI 681 & Boca de moça & Tanque/PI & Indeterminado & Branca com hilo rajado \\
\hline UFPI 676 & Boca de moça & Palmeirais/PI & Indeterminado & Branca com hilo rajado \\
\hline UFPI 652 & Boca de moça & Palmeirais/PI & Indeterminado & Branca com hilo rajado \\
\hline UFPI 500 & NI & Guaramiranga/CE & Indeterminado & Creme com hilo bege \\
\hline UFPI 274 & Fava Branca & Cajazeiras/PB & Indeterminado & Branca \\
\hline UFPI 651 & Boca de moça & Hugo Napoleão/PI & Indeterminado & Branca com hilo rajado \\
\hline UFPI 673 & Boca de moça & Barra D'alcantara/PI & Indeterminado & Branca com hilo rajado \\
\hline UFPI 669 & Boca de moça & Várzea Grande/PI & Indeterminado & Branca com hilo rajado \\
\hline UFPI 653 & Boca de moça & Barro Duro/PI & Indeterminado & Branca com hilo rajado \\
\hline UFPI 670 & Boca de moça & Várzea Grande/PI & Indeterminado & Branca com hilo rajado \\
\hline UFPI 668 & Boca de moça & Palmeirais/PI & Indeterminado & Branca com hilo rajado \\
\hline UFPI 689 & Boca de moça & Elesbão Veloso/PI & Indeterminado & Branca com hilo rajado \\
\hline
\end{tabular}

*Progênies 1 e 2 - descendências de plantas resistentes. NI = Não identificado. 
produtores da região (Tabela 1 ).

Para a obtenção das folhas, sementes de cada subamostra foram plantadas em vasos de plástico contendo $4,0 \mathrm{Kg}$ de terra vegetal adubada, conforme análise de solo, deixando-se uma planta/vaso após desbaste. Aos 40 dias após a semeadura, foram previamente selecionadas, de cada subamostra, oito folhas trifolioladas, completamente expandidas e com aproximadamente a mesma idade, $\mathrm{e}$ destacadas um dia antes da inoculação. Em seguida, as folhas foram acondicionadas em placas de Petri $(150 \times 20 \mathrm{~mm})$ esterilizadas contendo uma fina camada de algodão e um disco de papel de filtro umedecido com $20 \mathrm{~mL}$ de água, segundo metodologia descrita por Mendes \& Bergamin Filho (13).

$\mathrm{O}$ inóculo foi preparado adicionando-se $20 \mathrm{~mL}$ de água destilada esterilizada à placa do fungo, cultivado em meio de cultura FDA a $28 \pm 1^{\circ} \mathrm{C}$ e fotoperíodo de 12 horas, durante 15 dias, removendo-se as estruturas do patógeno com uma alça de platina em formato "o". Em seguida, a suspensão foi filtrada em filtro de café para separação dos esporos, e a concentração ajustada em $10^{5}$ esporos $/ \mathrm{mL}$, com o auxílio de uma câmara de Neubauer. A inoculação foi feita pulverizando-se a face superior e inferior da folha com aproximadamente $1,5 \mathrm{~mL}$ da suspensão de conídios (quatro folhas/subamostra) ou água esterilizada para as testemunhas (quatro folhas/subamostra). Após a inoculação, as placas foram fechadas com filme plástico transparente para manter uma umidade elevada. Após 48 horas, em incubadora com temperatura ajustada para $28 \pm 1^{\circ} \mathrm{C}$ e fotoperíodo de 12 horas, o filme plástico foi retirado e as folhas mantidas nessas condições até a avaliação.

A severidade foi avaliada por três avaliadores, aos cinco e sete dias após a inoculação (DAI), utilizando-se uma escala de notas de 0 a 5 , segundo Carvalho (6), em que: $0=$ ausência de sintomas; $1=$ traços a $10 \%$ da área foliar infectada; $2=11$ a $25 \%$ da área foliar infectada; $3=$ 26 a 50\% da área foliar infectada, sem queda de folíolo; $4=51$ a $75 \%$ da área foliar infectada, sem ou com queda de um dos folíolos; $5=76$ a $100 \%$ da área foliar infectada, sem ou com queda de dois ou três folíolos.

Após a avaliação da severidade, obteve-se uma média geral das notas atribuídas pelos avaliadores para cada subamostra. Com base nessas médias, as subamostras foram agrupadas segundo critérios estabelecidos por Belmino (2), em cinco classes: Imune (IM) - 0; altamente resistente (AR) - 0,1 a 1,4; moderadamente resistente (MR) - 1,5 a 2,4; moderadamente suscetível (MS) - 2,5 a 3,0; e altamente suscetível (AS) - acima de 3,0.

Utilizou-se o delineamento inteiramente casualizado, com quatro repetições. Cada repetição foi constituída por uma folha trifoliolada. Os dados da severidade foram submetidos à análise de variância, usando o software SAS. As médias transformadas em $\sqrt{x}_{\mathrm{x}}+1$ foram agrupadas pelo método proposto por Scott-knott $(\mathrm{P}<0,05 \%)$ e a comparação entre subamostras e testemunhas foi realizada pelo teste de Dunnett ( $\mathrm{P}<0,05 \%$ ) empregando-se o programa Genes.

\section{RESULTADOS E DISCUSSÃO}

\section{Avaliação da resistência das subamostras de feijão-fava à antracnose}

Observou-se que as reações das subamostras variaram de altamente resistente (AR) a altamente suscetível (AS) e que houve progresso na severidade da doença quando comparadas às resistências das subamostras aos cinco e sete dias após a inoculação (DAI) (Tabela 2).

Com relação à comparação entre as médias de severidade e reação das subamostras de feijão-fava a C. truncatum (Tabela 2), aos cinco e
Tabela 2. Médias ${ }^{1}$ de severidade (SEV) e reação $(\mathrm{R})$ das subamostras de feijão-fava a Colletotrichum truncatum, aos cinco e sete dias após a inoculação (DAI). Teresina-PI, 2010.

\begin{tabular}{|c|c|c|c|c|}
\hline \multirow[t]{2}{*}{ Subamostra } & \multicolumn{2}{|c|}{ Cinco DAI } & \multicolumn{2}{|c|}{ Sete DAI } \\
\hline & SEV & $\mathbf{R}^{2}$ & SEV & $\mathbf{R}^{2}$ \\
\hline Progênie $1^{3}$ & $0,75 \mathrm{~B}$ & AR & $2,00 \mathrm{~B}$ & MR \\
\hline Progênie $2^{3}$ & $1,00 \mathrm{~B}$ & AR & $2,50 \mathrm{~B}$ & MS \\
\hline UFPI 655 & $0,75 \mathrm{~B}$ & AR & $1,75 \mathrm{~B}$ & MR \\
\hline UFPI 220 & $0,75 \mathrm{~B}$ & AR & $2,25 \mathrm{~B}$ & MR \\
\hline UFPI 121 & $2,25 \mathrm{~A}$ & MR & $2,75 \mathrm{~B}$ & MS \\
\hline UFPI 251 & $0,25 \mathrm{~B}$ & AR & $1,25 \mathrm{~B}$ & AR \\
\hline UFPI 656 & $1,25 \mathrm{~B}$ & AR & $2,50 \mathrm{~B}$ & MS \\
\hline UFPI 667 & $2,50 \mathrm{~A}$ & MS & $4,00 \mathrm{~A}$ & AS \\
\hline UFPI 664 & $2,75 \mathrm{~A}$ & MS & $4,50 \mathrm{~A}$ & AS \\
\hline UFPI 276 & $3,50 \mathrm{~A}$ & AS & $4,00 \mathrm{~A}$ & AS \\
\hline UFPI 222 & $0,75 \mathrm{~B}$ & AR & $1,75 \mathrm{~B}$ & MR \\
\hline UFPI 465 & $4,00 \mathrm{~A}$ & AS & $5,00 \mathrm{~A}$ & AS \\
\hline UFPI 679 & $0,75 \mathrm{~B}$ & AR & $1,75 \mathrm{~B}$ & MR \\
\hline UFPI 658 & $3,75 \mathrm{~A}$ & AS & $4,25 \mathrm{~A}$ & AS \\
\hline UFPI 659 & $3,75 \mathrm{~A}$ & AS & $4,00 \mathrm{~A}$ & AS \\
\hline UFPI 032 & $3,75 \mathrm{~A}$ & AS & $4,00 \mathrm{~A}$ & AS \\
\hline UFPI 494 & $2,75 \mathrm{~A}$ & MS & $4,00 \mathrm{~A}$ & AS \\
\hline UFPI 470 & $1,75 \mathrm{~B}$ & MR & $2,50 \mathrm{~B}$ & MS \\
\hline UFPI 681 & $3,00 \mathrm{~A}$ & MS & $3,50 \mathrm{~A}$ & AS \\
\hline UFPI 676 & $2,00 \mathrm{~B}$ & MR & $3,25 \mathrm{~A}$ & AS \\
\hline UFPI 652 & $1,75 \mathrm{~B}$ & MR & $3,00 \mathrm{~A}$ & MS \\
\hline UFPI 500 & $2,25 \mathrm{~A}$ & MR & $3,25 \mathrm{~A}$ & AS \\
\hline UFPI 274 & $4,25 \mathrm{~A}$ & AS & $5,00 \mathrm{~A}$ & AS \\
\hline UFPI 651 & $4,25 \mathrm{~A}$ & AS & $4,75 \mathrm{~A}$ & AS \\
\hline UFPI 673 & $0,75 \mathrm{~B}$ & AR & $0,75 \mathrm{~B}$ & AR \\
\hline UFPI 669 & $3,75 \mathrm{~A}$ & AS & $5,00 \mathrm{~A}$ & AS \\
\hline UFPI 653 & $2,25 \mathrm{~A}$ & MR & $3,75 \mathrm{~A}$ & AS \\
\hline UFPI 670 & $1,75 \mathrm{~B}$ & MR & $2,50 \mathrm{~B}$ & MS \\
\hline UFPI 668 & $0,25 \mathrm{~B}$ & AR & $2,00 \mathrm{~B}$ & MR \\
\hline UFPI 689 & $3,00 \mathrm{~A}$ & MS & $4,25 \mathrm{~A}$ & AS \\
\hline CV (\%) & & & & \\
\hline
\end{tabular}

${ }^{1}$ Médias seguidas de mesma letra, na coluna, não diferem estatisticamente entre si pelo método de agrupamento de Scott-Knott $(\mathrm{P}<0,05 \%)$. Dados originais.

${ }^{2} \mathrm{IM}$ - Imune; AR - Altamente resistente; MR - Moderadamente resistente; MS - Moderadamente suscetível; AS - Altamente suscetível.

${ }^{3}$ Progênies 1 e 2 - descendências de plantas resistentes.

sete dias após a inoculação, verificou-se a formação de dois grupos (A e B). O grupo A, aos cinco DAI, foi constituído por dezesseis subamostras com severidade variando de 2,25 a 4,25, classificadas como AS (oito subamostras), MS (cinco subamostras) e MR (três subamostras). Por outro lado, o grupo B foi formado por quatorze subamostras com severidade variando de 0,25 a 2,00, sendo quatro MR e dez AR. Aos sete DAI, as subamostras foram separadas também em dois grupos, o grupo A formado por dezessete subamostras apresentando severidade variando de 3,25 a 5,00 (dezesseis AS e uma MS) e o grupo B constituído por treze subamostras, com severidade variando de 0,75 a 2,75 (cinco MS, seis MR e duas AR). Verificou-se 
que a maioria das subamostras altamente suscetíveis foram separadas das demais classes, compondo o grupo A. Estes resultados estão de acordo com Belmino (2), que apontou a severidade como o componente epidemiológico que melhor discriminou os genótipos de feijão-caupi quanto à reação de resistência à $C$. truncatum.

Comparando-se as avaliações realizadas aos cinco e sete DAI, observou-se que vinte subamostras mudaram de classe. Dentre estas, seis passaram de AR para MR; duas de AR para MS; quatro de MR para MS; três de MR para AS e cinco de MS para AS. Por outro lado, dez subamostras mantiveram-se na mesma classe, sendo oito AS (UFPI 276, UFPI 465, UFPI 658, UFPI 659, UFPI 032, UFPI 274, UFPI 651 e UFPI 669) e duas AR (UFPI 251 e UFPI 673). O tempo para o aparecimento de sintomas está relacionado com o comportamento hemibiotrófico do gênero Colletotrichum (14), resistência do hospedeiro e virulência do isolado (8). De acordo com Chongo et al. (8), em cultivar suscetível de lentilhas, o tempo de aparecimento das lesões variou de 72 a 144 horas e de até 14 dias após a inoculação, em cultivar resistente. Desta forma, a mudança de comportamento das subamostras de feijão-fava constatada pode está relacionada a esses fatores.

Estudos de avaliação de genótipos de feijão-fava quanto à resistência à antracnose são escassos, diferentemente do que ocorre em outras culturas. Nessa espécie, encontrou-se apenas um registro, Carvalho (6), que classificou os três genótipos avaliados como suscetíveis ao fungo, embora cite que outras subamostras podem apresentar resistência. Desta forma, os resultados encontrados corroboram com o autor, visto que dentre as 30 subamostras avaliadas, UFPI 673 e UFPI 251 se comportaram como altamente resistentes, aos cinco e sete DAI. Para outras culturas existem vários relatos de materiais resistentes ao fungo $(2,3,16,18)$. Costa et al. (9) avaliando a reação de 48 cultivares comerciais de soja a C. truncatum, também encontraram diferentes classes, sendo apenas três cultivares suscetíveis, e as demais consideradas resistentes (17 cultivares) ou intermediárias (28 cultivares). Belmino (2), trabalhando com resistência de genótipos de feijão-caupi a $C$. truncatum em Teresina e José de Freitas-PI, também constatou variações na resistência dos genótipos de imunes à altamente suscetíveis.

As duas subamostras AR (UFPI 673 e UFPI 251), apesar de serem oriundas dos estados do Piauí e Minas Gerais, respectivamente (Tabela 1) foram agrupadas pelo método de Scott-knott em mesmo grupo (B) aos cinco e sete dias. Esse fato pode indicar uma semelhança genética entre elas. Contudo, Belmino (2) observou muita variação entre ensaios quanto à resistência de genótipos de feijão-caupi à $C$. truncatum. Segundo esse autor, genótipos considerados resistentes para determinado local e condições foram suscetíveis em outro, indicando haver variabilidade entre isolados do fungo.

A comparação entre as subamostras de feijão-fava com suas respectivas testemunhas (Tabela 3), mostra que aos cinco DAI, 14 subamostras classificadas como AR, MR e MS na avaliação da severidade (Tabela 2) foram iguais às testemunhas, enquanto, aos sete DAI, somente sete subamostras (uma AR, duas MR, três MS e uma AS) mantiveram o mesmo comportamento. As testemunhas apresentaram sintomas com severidade variando de 0,00 a 1,00, aos cinco e sete DAI. Resultados semelhantes foram encontrados por Carmo (5) ao avaliar a reação de feijão-fava de crescimento determinado à $C$. truncatum. Segundo o autor a presença de sintomas nas testemunhas foi provavelmente devido à ocorrência natural de esporos do fungo no ambiente.

As subamostras que não diferiram das testemunhas (Tabela 3) e não se comportaram como AR quando avaliadas em folhas destacadas podem ser AR no campo. Buchwaldt et al. (3), em estudos de identificação de germoplasma de lentilha resistente a C. truncatum,
Tabela 3. Médias ${ }^{1}$ das subamostras e das respectivas testemunhas, aos cinco e sete dias após a inoculação (DAI). Teresina-PI, 2010.

\begin{tabular}{|c|c|c|c|c|}
\hline \multirow[b]{2}{*}{ Subamostras } & \multicolumn{2}{|c|}{ Cinco DAI } & \multicolumn{2}{|c|}{ Sete DAI } \\
\hline & $\begin{array}{l}\text { Médias das } \\
\text { subamostras }\end{array}$ & $\begin{array}{l}\text { Médias das } \\
\text { testemunhas }\end{array}$ & $\begin{array}{l}\text { Médias das } \\
\text { subamostras }\end{array}$ & $\begin{array}{l}\text { Médias das } \\
\text { testemunhas }\end{array}$ \\
\hline Progênie $1^{2}$ & $0,75 \mathrm{~A}$ & $0,00 \mathrm{~B}$ & $2,00 \mathrm{~A}$ & $0,00 \mathrm{~B}$ \\
\hline Progênie $2^{2}$ & $1,00 \mathrm{~A}$ & $0,00 \mathrm{~B}$ & $2,50 \mathrm{~A}$ & $0,00 \mathrm{~B}$ \\
\hline UFPI 655 & $0,75 \mathrm{~A}$ & $0,00 \mathrm{~A}$ & $1,75 \mathrm{~A}$ & $0,00 \mathrm{~B}$ \\
\hline UFPI 220 & $0,75 \mathrm{~A}$ & $0,00 \mathrm{~B}$ & $2,25 \mathrm{~A}$ & $0,00 \mathrm{~A}$ \\
\hline UFPI 121 & $2,25 \mathrm{~A}$ & $0,50 \mathrm{~A}$ & $2,75 \mathrm{~A}$ & $0,75 \mathrm{~A}$ \\
\hline UFPI 251 & $0,25 \mathrm{~A}$ & $0,00 \mathrm{~A}$ & $1,25 \mathrm{~A}$ & $0,00 \mathrm{~B}$ \\
\hline UFPI 656 & $1,25 \mathrm{~A}$ & $0,25 \mathrm{~A}$ & $2,50 \mathrm{~A}$ & $0,25 \mathrm{~B}$ \\
\hline UFPI 667 & $2,50 \mathrm{~A}$ & $0,00 \mathrm{~B}$ & $4,00 \mathrm{~A}$ & $0,00 \mathrm{~B}$ \\
\hline UFPI 664 & $2,75 \mathrm{~A}$ & $0,25 \mathrm{~B}$ & $4,50 \mathrm{~A}$ & $0,25 \mathrm{~B}$ \\
\hline UFPI 276 & $3,50 \mathrm{~A}$ & $0,25 \mathrm{~B}$ & $4,00 \mathrm{~A}$ & $0,25 \mathrm{~B}$ \\
\hline UFPI 222 & $0,75 \mathrm{~A}$ & $0,00 \mathrm{~B}$ & $1,75 \mathrm{~A}$ & $0,00 \mathrm{~B}$ \\
\hline UFPI 465 & $4,00 \mathrm{~A}$ & $0,00 \mathrm{~B}$ & $5,00 \mathrm{~A}$ & $0,00 \mathrm{~B}$ \\
\hline UFPI 679 & $0,75 \mathrm{~A}$ & $0,00 \mathrm{~B}$ & $1,75 \mathrm{~A}$ & $0,00 \mathrm{~B}$ \\
\hline UFPI 658 & $3,75 \mathrm{~A}$ & $0,25 \mathrm{~B}$ & $4,25 \mathrm{~A}$ & $0,25 \mathrm{~B}$ \\
\hline UFPI 659 & $3,75 \mathrm{~A}$ & $0,50 \mathrm{~B}$ & $4,00 \mathrm{~A}$ & $0,75 \mathrm{~B}$ \\
\hline UFPI 032 & $3,75 \mathrm{~A}$ & $0,00 \mathrm{~B}$ & $4,00 \mathrm{~A}$ & $0,00 \mathrm{~B}$ \\
\hline UFPI 494 & $2,75 \mathrm{~A}$ & $0,00 \mathrm{~A}$ & $4,00 \mathrm{~A}$ & $0,25 \mathrm{~B}$ \\
\hline UFPI 470 & $1,75 \mathrm{~A}$ & $0,25 \mathrm{~A}$ & $2,50 \mathrm{~A}$ & $0,25 \mathrm{~B}$ \\
\hline UFPI 681 & $3,00 \mathrm{~A}$ & $0,75 \mathrm{~A}$ & $3,50 \mathrm{~A}$ & $0,75 \mathrm{~B}$ \\
\hline UFPI 676 & $2,00 \mathrm{~A}$ & $0,00 \mathrm{~A}$ & $3,25 \mathrm{~A}$ & $0,00 \mathrm{~B}$ \\
\hline UFPI 652 & $1,75 \mathrm{~A}$ & $0,25 \mathrm{~A}$ & $3,00 \mathrm{~A}$ & $0,75 \mathrm{~A}$ \\
\hline UFPI 500 & $2,25 \mathrm{~A}$ & $0,50 \mathrm{~A}$ & $3,25 \mathrm{~A}$ & $1,00 \mathrm{~A}$ \\
\hline UFPI 274 & $4,25 \mathrm{~A}$ & $0,00 \mathrm{~B}$ & $5,00 \mathrm{~A}$ & $0,25 \mathrm{~B}$ \\
\hline UFPI 651 & $4,25 \mathrm{~A}$ & $0,00 \mathrm{~B}$ & $4,75 \mathrm{~A}$ & $0,00 \mathrm{~B}$ \\
\hline UFPI 673 & $0,75 \mathrm{~A}$ & $0,25 \mathrm{~A}$ & $0,75 \mathrm{~A}$ & $0,25 \mathrm{~A}$ \\
\hline UFPI 669 & $3,75 \mathrm{~A}$ & $0,25 \mathrm{~B}$ & $5,00 \mathrm{~A}$ & $0,25 \mathrm{~B}$ \\
\hline UFPI 653 & $2,25 \mathrm{~A}$ & $0,00 \mathrm{~A}$ & $3,75 \mathrm{~A}$ & $0,00 \mathrm{~B}$ \\
\hline UFPI 670 & $1,75 \mathrm{~A}$ & $0,00 \mathrm{~A}$ & $2,50 \mathrm{~A}$ & $0,00 \mathrm{~A}$ \\
\hline UFPI 668 & $0,25 \mathrm{~A}$ & $0,00 \mathrm{~A}$ & $2,00 \mathrm{~A}$ & $0,00 \mathrm{~A}$ \\
\hline UFPI 689 & $3,00 \mathrm{~A}$ & $0,00 \mathrm{~B}$ & $4,25 \mathrm{~A}$ & $0,00 \mathrm{~B}$ \\
\hline
\end{tabular}

${ }^{1}$ Médias seguidas de mesma letra na linha não diferem da testemunha pelo teste de Dunnett $(\mathrm{P}<0,05 \%)$. Dados originais.

${ }^{2}$ Progênies 1 e 2 - descendências de plantas resistentes.

verificaram que os genótipos resistentes à antracnose no campo comportaram-se como suscetíveis quando avaliados em condições controladas. Resultado semelhante também foi encontrado por Gonçalves et al. (10), em estudo sobre resistência de soja ao oídio, no qual as cultivares que apresentaram reação moderadamente resitente ou suscetível em folhas destacadas e em casa de vegetação foram resistentes no campo.

Algumas subamostras que tiveram média de notas igual a 0,75 aos cinco DAI, não foram iguais à testemunha. Já outras subamostras com nota igual ou superior a 0,75 aos cinco DAI e aos sete DAI, foram iguais às suas testemunhas. Este fato ocorreu devido provavelmente à variação na severidade verificada dentro das repetições de cada subamostra em função de vários fatores. Segundo Chongo \& Bernier (7), o desenvolvimento da antracnose causado por $C$. truncatum em lentilha depende do genótipo do hospedeiro, concentração de inóculo, 
duração do período de molhamento, fase de crescimento e temperatura. A diferença na idade das folhas destacadas também pode ter contribuído para esses resultados, tendo em vista que todas as subamostras avaliadas são de crescimento indeterminado (Tabela 1) dificultando a escolha de folhas de mesma idade. Segundo Carvalho (6), a idade das folhas selecionadas para inoculação pode ter contribuído para as divergências de comportamento dos genótipos de feijão-fava quando avaliados em folhas destacadas e plantas. Nechet \& Halfeld-Vieira (15) ao avaliarem a reação de resistência de feijão-caupi a Rhizoctonia solani também constataram que o estádio fenológico da planta influencia na resistência. De acordo com os autores, a resistência diminuiu com o avançar do ciclo de desenvolvimento da planta. Belmino (2), avaliando a reação de genótipos de feijão-caupi a $C$. truncatum observou que as plantas inoculadas com uma e duas semanas após o plantio apresentaram menores valores de severidade, enquanto em planta com três semanas de idade a severidade foi maior.

As condições do ambiente influenciam a reações do hospedeiro aos patógenos. No entanto, Carvalho (6), ao avaliar a reação de subamostras de feijão-fava a C. truncatum em período chuvoso e seco, constatou que os fatores climáticos influenciaram no comportamento dos genótipos ao fungo sem, contudo, revelar diferença entre as duas épocas quando avaliados em folha destacada.

O uso de genótipos de feijão-fava com resistência à antracnose poderá ser útil na redução do uso de defensivos e contribuir para a elevação no rendimento da cultura, com menores custos de produção. As subamostras UFPI 673 e UFPI 251, altamente resistentes aos cinco e sete DAI, mostraram-se promissoras para ser utilizadas em futuros programas de melhoramento visando resistência à antracnose.

Em folhas destacadas, a maioria das subamostras de feijão-fava avaliada apresentou baixo nível de resistência à antracnose;

As subamostras UFPI 251 e UFPI 673 foram altamente resistentes aos cinco e sete dias após a inoculação quando avaliadas em condições de folha destacada, sendo, portanto promissoras para utilização em programas de melhoramento da cultura.

\section{AGRADECIMENTOS}

Agradecemos à Fundação de Amparo a Pesquisa do Piauí (FAPEPI) pela concessão da bolsa e ao Banco Ativo de Germoplasma (BAG de Feijão-fava) da UFPI pelo fornecimento das sementes.

\section{REFERÊNCIAS BIBLIOGRÁFICAS}

1. Azevedo, J. N.; Franco, L. J. D.; Araujo, R. O. C. Composição química de sete variedades de feijão-fava. Teresina: Embrapa Meio-Norte, 2003. 4p.

2. Belmino, C. S. Resistência do feijão-caupi a Colletotrichum truncatum. 2004. 64f. Tese (Doutorado em Fitopatologia) - Universidade Federal de Viçosa, Viçosa.

3. Buchwaldt, L.; Anderson, K. L.; Morrall, R. A. A.; Gossen, B. D.; Bernier, C. C. Identification of lentil germ plasm resistant to Colletotrichum truncatum and characterization of two pathogen races. Phytophatology, St. Paul, v.94, n.3, p.236-243, 2004.

4. Camargo, L. E. A.; Bergamin Filho, A. Controle genético. In.: Bergamin Filho, A.; Kimati, H.; Amorim, L. Manual de Fitopatologia: princípios e conceitos. 3. ed. São Paulo: Agronômica Ceres, 1995. v.1, cap37, p.729-758.

5. Carmo, M. D. S. Variabilidade genética e reação ao Colletotrichum truncatum em feijão-fava de crescimento determinado. $2011.132 \mathrm{f}$.
Dissertação (Mestrado em Genética e Melhoramento) - Universidade Federal do Piauí, Teresina.

6. Carvalho, E. M. S. Antracnose em feijão-fava (Phaseolus lunatus L.): Caracterização do agente causal e reação de genótipos a Colletotrichum truncatum. 2009. 53f. Tese (Doutorado em Agronomia) - Faculdade de Ciências Agrárias e Veterinárias, Universidade Estadual Paulista, Jaboticabal.

7. Chongo, G.; Bernier, C. C. Effects of host, inoculum concentration, wetness duration, growth stage, and temperature on anthracnose of lentil. Plant Disease, St. Paul, v.84, n.5, p.544-548, 2000.

8. Chongo, G.; Gossen, B. D.; Bernier, C. C. Infection by Colletotrichum truncatum in resistant and susceptible lentil genotypes. Canadian Journal Plant Pathology, Ottawa, v.24, n.1, p.81-85, 2001.

9. Costa, I. F. D.; Balardin, R. S.; Medeiros, L. A. M.; Lenz, G. L.; Gulart, C. A.; Zemolin, C. R.; Silva, T. M. B. Reação de germoplasma comercial de soja a Colletotrichum truncatum. Tropical Plant Pathology, Brasília, DF, v.34, n.1, p.47-50, 2009.

10. Gonçalves, E. C. P.; Centurion, M. A. P. C.; Di Mauro, A. O. Avaliação da reação de genótipos de soja ao oídio em diferentes condições. Summa Phytopathologica, Botucatu, v.35, n.2, p.151-153, 2009.

11. Guimarães, W. N. R.; Martins, L. S. S.; Silva, E. F.; Ferraz, G. M. G.; Oliveira, F. J. Caracterização morfológica e molecular de acessos de feijão-fava (Phaseolus lunatus L.). Revista Brasileira de Engenharia Agrícola e Ambiental, Campina Grande, v.11, n.1, p.37-45, 2007.

12. Medeiros, J. G. S. Reação de genótipos de pessegueiro a bacteriose causada por Xanthomonas arboricola pv. Pruni. 2009. 79f. Dissertação (Mestrado em Agronomia) - Universidade Tecnológica Federal do Paraná, Pato Branco.

13. Mendes, B. M. J.; Bergamin Filho, A. Adaptação da técnica da cultura de folha destacada para quantificação dos parâmetros epidemiológicos monocíclicos da ferrugem do feijoeiro (Uromices phaseoli var. typica). Fitopatologia Brasileira, Brasília, DF, v.11, n.1, p. 103-114, 1986.

14. Münch, S.; Lingner, U.; Floss, D.S.; Ludwig, N.; Sauer, N.; Deising, H.B. The hemibiotrophic lifestyle of Colletotrichum species. Journal of Plant Physiology, v. 165, n.1, p. 41-51, 2008.

15. Nechet, K.L.; Halfeld-Vieira, B. A. Efeito do inóculo, período de molhamento foliar e do estádio fenológico do feijão-caupi no desenvolvimento da mela. Tropical Plant Pathology, Brasília, DF, v.36, n.2, p.104$109,2011$.

16. Nechet, K. L.; Halfeld-Vieira, B. A.; Gianluppi, V.; Meyer, M. C. Avaliação de genótipos de soja em relação à antracnose (Colletotrichum truncatum) e mela (Tanatephorus cucumeris) nas condições de Roraima, Roraima: Embrapa Roraima. 2004. 16p.

17. Paula Júnior, T. J.; Silva, M. B.; Vieira, R. F. Doenças causadas por fungos em hortaliças leguminosas. Informe Agropecuário, Belo Horizonte, v.17, n.182, p.63-71, 1995.

18. Pereira, M. J. Z.; Massola Junior, N. S.; Sussel, A. A. B.; Sala, F. C.; Costa, C. P.; Boiteux, L. S. Reação de acessos de Capsicum e de progênies de cruzamentos interespecíficos a isolados de Colletotrichum acutatum. Horticultura Brasileira, Brasília, DF, v. 29, n. 4, p.569-576, 2011.

19. Rios, G. P., Andrade, E. M.; Costa, J. L. S. Avaliação da resistência de cultivares e linhagens do feijoeiro comum a diferentes populações de Uromyces appendiculatus. Fitopatologia Brasileira, Brasília, DF, v.26, n.2, p.128-133, 2001

20. Santos, D.; Corlett, F. M. F.; Mendes, J. E. M. F.; Wanderley Júnior, J. S. A. Produtividade e morfologia de vagens e sementes de variedades de fava no Estado da Paraíba. Pesquisa Agropecuária Brasileira, Brasília, DF, v.37, n.10, p.1407-1412, 2002.

21. Santos, J. O.; Araújo, A. S. F.; Gomes, R. L. F.; Lopes, A. C. A. Figueiredo, M. V. B. Ontogenia da nodulação em feijão-fava (Phaseolus lunatus), Revista Brasileira de Ciências Agrárias, Recife, v.4, n.4, p.426-429, 2009.

22. Sauer, J. D. Historical geography of crop plants: a select roster. Florida: CRC, 1993. 309p.

23. Zimmermann, M. J. O.; Teixeira, M. G. Origem e evolução. In: Araújo, R. S.; Rava, C. A.; Stone, L. F.; Zimmermann, M. J. O. Cultura do feijoeiro comum no Brasil. Piracicaba: Potafos, 1996. p. $57-70$. 